\title{
Volume-Targeted Versus Pressure-Limited Noninvasive Ventilation in Subjects With Acute Hypercapnic Respiratory Failure: A Multicenter Randomized Controlled Trial
}

\author{
Zhixin Cao MD, Zujin Luo MD, Anna Hou MD, Qingrong Nie MD, Baoyuan Xie MD, \\ Xiaojie An MD, Zifen Wan MD, Xianwei Ye MD, Yanju Xu MD, Xisheng Chen MD, \\ Honghai Zhang MD, Zhenyang Xu MD, Jinxiang Wang MD, Fucheng An MD, Pengfei Li MD, \\ Chunxiao Yu MD, Yandong Liang MD, Yongxiang Zhang MD, and Yingmin Ma MD
}

BACKGROUND: Volume-targeted noninvasive ventilation (VT-NIV), a hybrid mode that delivers a preset target tidal volume $\left(\mathrm{V}_{\mathrm{T}}\right)$ through the automated adjustment of pressure support, could guarantee a relatively constant target $\mathbf{V}_{T}$ over pressure-limited noninvasive ventilation (PL-NIV) with fixed-level pressure support. Whether VT-NIV is more effective in improving ventilatory status in subjects with acute hypercapnic respiratory failure (AHRF) remains unclear. Our aim was to verify whether, in comparison with PL-NIV, VT-NIV would be more effective in correcting hypercapnia, hence reducing the need for intubation and improving survival in subjects with AHRF. METHODS: We performed a prospective randomized controlled trial in the general respiratory wards of 8 university-affiliated hospitals in China over a 12-month period. Subjects with AHRF, defined as arterial $\mathrm{pH}<7.35$ and $\geq 7.25$ and $\mathrm{P}_{\mathrm{aCO}}>45 \mathrm{~mm} \mathrm{Hg}$, were randomly assigned to undergo PL-NIV or VT-NIV. The primary end point was the decrement of $\mathbf{P}_{\mathrm{aCO}_{2}}$ from baseline to $6 \mathrm{~h}$ after randomization. Secondary end points included the decrement of $\mathrm{PaCO}_{2}$ from baseline to $2 \mathrm{~h}$ after randomization as well as outcomes of subjects (eg, need for intubation, in-hospital mortality). RESULTS: A total of 58 subjects were assigned to PL-NIV (29 subjects) or VT-NIV (29 subjects) and included in the analyses. The decrement of $\mathrm{P}_{\mathrm{aCO}}$ from baseline to $6 \mathrm{~h}$ after randomization was not statistically different between the PL-NIV group and the VT-NIV group $(9.3 \pm 12.6 \mathrm{~mm} \mathrm{Hg}$ vs $11.7 \pm 12.9 \mathrm{~mm} \mathrm{Hg}, P=.48$ ). There were no differences between the PL-NIV group and the VT-NIV group in the decrement of $P_{\mathrm{aCO}}$, from baseline to $2 \mathrm{~h}$ after randomization $(6.4 \pm 12.7 \mathrm{~mm} \mathrm{Hg}$ vs $5.0 \pm 15.8 \mathrm{~mm} \mathrm{Hg}, P=.71)$ as well as in the need for intubation $(17.2 \%$ vs $10.3 \%, P=.70)$, and in-hospital mortality $(10.3 \%$ vs $6.9 \%, P>.99)$. CONCLUSIONS: Regardless of whether a VT- or PL-NIV strategy is employed, it is possible to provide similar support to subjects with AHRF. (ClinicalTrials.gov registration NCT02538263.) Key words: acute hypercapnic respiratory failure; noninvasive ventilation; volume-targeted; pressure-limited; target tidal volume; hypercapnia. [Respir Care 2016;61(11):1440-1450. (C) 2016 Daedalus Enterprises]

\section{Introduction}

Noninvasive ventilation (NIV) is increasingly being used in the care of subjects suffering acute respiratory failure. ${ }^{1-5}$

Drs Cao, Luo, Hou, and Ma are affiliated with the Department of Respiratory and Critical Care Medicine, Beijing Engineering Research Center of Respiratory and Critical Care Medicine, Beijing Institute of Respiratory Medicine, Beijing Chao-Yang Hospital, Capital Medical University, Beijing, China. Drs Nie, Xie, and Xiaojie An are affiliated
Several lines of evidence strongly support its use in subjects with acute respiratory failure due to COPD exacerbations, ${ }^{6-12}$ acute cardiogenic pulmonary edema, ${ }^{13-16}$ and immunocompromised states ${ }^{17,18}$ as well as in facilitating

with the Department of Respiratory Medicine, Liangxiang Hospital of Beijing Fangshan District, Beijing, China. Drs Wan, Ye, and Xu are affiliated with the Department of Respiratory and Critical Care Medicine, The People's Hospital of Guizhou Province, Guiyang, Guizhou, China. 
early liberation from invasive ventilation. ${ }^{19-21}$ However, pressure-limited NIV (PL-NIV) with fixed-level pressure support, the most commonly used mode in clinical studies and practice, ${ }^{22,23}$ cannot ensure the delivered tidal volume $\left(\mathrm{V}_{\mathrm{T}}\right)$ to a constant target value, because the $\mathrm{V}_{\mathrm{T}}$ varies depending on dynamic changes in inspiratory effort, airway resistance, and chest-wall and lung compliance. ${ }^{24,25}$ By contrast, volume-targeted NIV (VT-NIV), a hybrid

\section{See the Related Editorial on Page 1562}

mode in which the ventilator measures or estimates delivered $\mathrm{V}_{\mathrm{T}}$ through a built-in pneumotachograph and automatically adjusts pressure support within a preset range to provide a $\mathrm{V}_{\mathrm{T}}$ as close as possible to a target $\mathrm{V}_{\mathrm{T}}$ set by the physician, is able to guarantee a target $\mathrm{V}_{\mathrm{T}}$ that is relatively constant compared with PL-NIV with fixed-level pressure support. ${ }^{26}$ Conceivably, VT-NIV may be more beneficial in improving ventilatory status than PL-NIV, particularly in subjects with acute hypercapnic respiratory failure (AHRF), for whom it is of critical importance to efficiently improve ventilatory status.

The majority of previous studies on VT-NIV have been performed mainly in subjects with obesity hypoventilation syndrome $26-28$ and chronic respiratory failure. ${ }^{29-31}$ In subjects with AHRF, there has been only one study performed to date; this study showed that VT-NIV was more effective in correcting $\mathrm{P}_{\mathrm{CO}_{2}}$ levels and facilitating the recovery of consciousness than PL-NIV. ${ }^{32}$ However, as acknowledged

Drs Chen and Honghai Zhang are affiliated with the Department of Respiratory Medicine, Beijing Shunyi District Hospital, Beijing, China. Dr Wang is affiliated with the Department of Respiratory and Critical Care Medicine, Beijing Luhe Hospital, Capital Medical University, Beijing, China. Drs Fucheng An and Li are affiliated with the Department of Respiratory Medicine, Beijing Mentougou District Hospital, Beijing, China. Drs Yu and Liang are affiliated with the Department of Respiratory Medicine, Beijing Jingmei Group General Hospital, Beijing, China. Dr Yongxiang Zhang is affiliated with the Department of Respiratory Medicine, Daxing Teaching Hospital, Capital Medical University, Beijing, China.

Drs Cao and Luo contributed equally to this work. The authors have disclosed no conflicts of interest.

Correspondence: Zhixin Cao MD, Department of Respiratory and Critical Care Medicine, Beijing Engineering Research Center of Respiratory and Critical Care Medicine, Beijing Institute of Respiratory Medicine, Beijing Chao-Yang Hospital, Capital Medical University, 5 Jingyuan Road, Shijingshan District, Beijing 100043, China. E-mail: caozhixinicu@126.com. Yingmin Ma MD, Department of Respiratory and Critical Care Medicine, Beijing Engineering Research Center of Respiratory and Critical Care Medicine, Beijing Institute of Respiratory Medicine, Beijing Chao-Yang Hospital, Capital Medical University, 5 Jingyuan Road, Shijingshan District, Beijing 100043, China. E-mail: ma.yingmin@163.com.

DOI: $10.4187 /$ respcare.04619

\section{QUICK LOOK}

\section{Current knowledge}

NIV is typically delivered using a pressure-limited NIV mode (PL-NIV) with a fixed pressure support, and the delivered tidal volume $\left(\mathrm{V}_{\mathrm{T}}\right)$ varies depending on inspiratory effort and respiratory mechanics. Volume-targeted noninvasive ventilation (VT-NIV), a hybrid mode that delivers a target $\mathrm{V}_{\mathrm{T}}$ by automated adjustment of pressure support, may guarantee a relatively constant target $\mathrm{V}_{\mathrm{T}}$ over PL-NIV with fixed-level pressure support. However, VT-NIV has seldom been described in subjects with acute hypercapnic respiratory failure, in whom it is of critical importance to efficiently improve ventilatory status.

\section{What this paper contributes to our knowledge}

This study compared VT-NIV and PL-NIV in subjects with AHRF. No significant differences were found in the decrement of $\mathrm{P}_{\mathrm{aCO}}$, need for intubation, or in-hospital mortality between the 2 groups.

by its authors, this study was a case-control study, without randomization and with a small sample size. Therefore, whether VT-NIV in such subjects is more effective in improving ventilatory status than PL-NIV remains to be assessed.

We postulated that the use of VT-NIV would be more effective in correcting hypercapnia than PL-NIV, due to its advantage in providing a relatively constant target $\mathrm{V}_{\mathrm{T}}$, hence reducing the need for intubation and improving survival in subjects with AHRF. Accordingly, we conducted a prospective randomized controlled trial to assess the efficacy of VT-NIV in comparison with PL-NIV.

\section{Methods}

\section{Subjects}

We conducted a prospective randomized controlled trial in the general respiratory wards of 8 university-affiliated hospitals in China. All of the wards had staff experienced in delivering NIV. Systematic training for the diagnosis and treatment of AHRF as well as NIV application to AHRF was performed before recruiting subjects. The protocol was approved by the ethics committee at each hospital, and written informed consent was obtained from all subjects, their next of kin, or other surrogate decision makers, as appropriate.

Patients were considered eligible for the study if they were diagnosed with AHRF, defined as arterial $\mathrm{pH}<7.35$ and $\geq 7.25$ with $\mathrm{P}_{\mathrm{aCO}_{2}}>45 \mathrm{~mm} \mathrm{Hg}$. Patients with $\mathrm{pH}$ $<7.25$ were not included, because such individuals are conventionally transferred to the ICU due to the severity 
of their illness. Exclusion criteria were as follows: age $<18$ y; excessive amount of respiratory secretions or weak cough; upper airway obstruction; recent oral, facial, or cranial trauma or surgery; recent gastric or esophageal surgery; severe abdominal distention; active upper gastrointestinal bleeding; cardiac or respiratory arrest; $\mathrm{P}_{\mathrm{O}_{2}} / \mathrm{F}_{\mathrm{IO}_{2}}$ $<150 \mathrm{~mm} \mathrm{Hg}$; pneumothorax; severe ventricular arrhythmia or myocardial ischemia; severe hemodynamic instability despite fluid repletion and use of vasoactive agents; severe metabolic acidosis; lack of cooperation; and refusal to receive NIV.

\section{Randomization}

Randomization was accomplished by a computer-generated random number sequence, which was stratified according to the study center. The allocation sequence was concealed from the coordinating center by the use of numbered, opaque, and sealed envelopes. An independent telephone contact system was used for randomization. All of the centers participating in the study were immediately put in contact with the coordinating center to obtain a randomization number if a subject fulfilled the inclusion criteria. Within $1 \mathrm{~h}$ after the validation of inclusion criteria, subjects were randomly assigned to undergo either PL-NIV or VT-NIV in a 1:1 ratio.

\section{Interventions}

Both modes of ventilation were provided by the same noninvasive ventilator (FLEXO ST30, CURATIVE Medical, Suzhou, China). For PL-NIV, the inspiratory positive airway pressure (IPAP) was initially set at $10 \mathrm{~cm} \mathrm{H}_{2} \mathrm{O}$ and was continuously adjusted by increments/decrements of 1-2 $\mathrm{cm} \mathrm{H}_{2} \mathrm{O}$, according to subjects' tolerance (up to $25 \mathrm{~cm}$ $\mathrm{H}_{2} \mathrm{O}$ ), to obtain a $\mathrm{V}_{\mathrm{T}}$ of $8-10 \mathrm{~mL} / \mathrm{kg}$ of predicted body weight and a breathing frequency of $<25$ breaths/min over NIV use. For VT-NIV, the target $\mathrm{V}_{\mathrm{T}}$ was set at $10 \mathrm{~mL} / \mathrm{kg}$ of predicted body weight, with IPAP ranging from 10 up to $25 \mathrm{~cm} \mathrm{H}_{2} \mathrm{O}$. For both modes, expiratory positive airway pressure (EPAP) was set at 5-8 $\mathrm{cm} \mathrm{H}_{2} \mathrm{O}$, backup frequency was set at 10 breaths $/ \mathrm{min}$, rise time was set at $25-200 \mathrm{~ms}$, and inspiratory time was set at a minimum of $0.5 \mathrm{~s}$ and a maximum of $2.0 \mathrm{~s}$. An oronasal mask (Bestfit2 face mask, CURATIVE Medical) was used as a first choice for all subjects, but a nasal mask (Bestfit2 nasal mask, CURATIVE Medical) was optional if subjects did not tolerate the oronasal mask. A disposable single limb circuit was used, and a leak port was incorporated into the mask. Supplemental oxygen was supplied for all subjects through a port in the mask, with the flow adjusted to maintain oxygen saturation between 90 and $95 \%$.

All subjects were encouraged to use NIV as much as possible during the first $6 \mathrm{~h}$ after randomization and at least $10 \mathrm{~h} / \mathrm{d}$. They were rigorously monitored at the bedside to ensure optimal NIV use. Disconnection from the ventilator was allowed for short periods, to clear secretions, drink water, or eat food, but was not scheduled.

In all subjects, the levels of IPAP and EPAP and the daily use of NIV were gradually decreased under conditions of clinical stability. Attempts to withdraw NIV were made if IPAP was $10 \mathrm{~cm} \mathrm{H}_{2} \mathrm{O}$ for PL-NIV or ranged from 10 to $12 \mathrm{~cm} \mathrm{H}_{2} \mathrm{O}$ for VT-NIV and if EPAP was $5 \mathrm{~cm} \mathrm{H}_{2} \mathrm{O}$ and daily use was $<5 \mathrm{~h}$ for both modes. Weaning was considered successful if subjects were able to sustain spontaneous breathing without signs of respiratory distress within $72 \mathrm{~h}$ after withdrawal, defined as the presence of $\geq 2$ of the following: arterial $\mathrm{pH}<7.35$; frequency $>30$ breaths/min; $\mathrm{P}_{\mathrm{aO}_{2}}<60 \mathrm{~mm} \mathrm{Hg}$ or $\mathrm{S}_{\mathrm{pO}_{2}}<90 \%$ at $\mathrm{F}_{\mathrm{IO}_{2}}$ $\geq 0.4$; retraction of the intercostal spaces, use of accessory respiratory muscles, or thoracic-abdominal paradoxical movement; and decreased consciousness, agitation, or diaphoresis. $^{33}$

Endotracheal intubation was considered if either of the following criteria were met: arterial $\mathrm{pH}<7.25$ with $\mathrm{P}_{\mathrm{aCO}_{2}}$ increased by $>20 \%$ compared with the baseline or $\mathrm{P}_{\mathrm{aO}_{2}}$ $<60 \mathrm{~mm} \mathrm{Hg}$ despite maximum tolerated supplemental oxygen, and if at least one of the following criteria were met: clinical signs suggestive of severely decreased consciousness (eg, coma, delirium); excessive amount of respiratory secretions with weak cough; use of accessory respiratory muscles or thoracic-abdominal paradoxical movement; severe upper gastrointestinal bleeding with aspiration or vomiting; or severe hemodynamic instability despite fluid repletion and use of vasoactive agents. Once a subject fulfilled these criteria, the final decision for intubation was made by the attending physician with the consent of subjects' next of kin or other surrogate decision makers, as appropriate, which meant that subjects in both groups who met intubation criteria could be intubated or noninvasively ventilated.

The end of the protocol was defined as: presence of intubation criteria, with or without intubation; termination of NIV resulting from intolerance; death; hospital discharge; or $28 \mathrm{~d}$ after randomization.

\section{Measurements and Outcomes}

At enrollment, data with respect to the subjects' demographic characteristics, underlying disease, and history of NIV use were recorded. Vital signs were recorded at baseline (before randomization) and at 1, 2, 3, 4, 5, and $6 \mathrm{~h}$ after randomization. Arterial blood gases and supplemental oxygen flow were recorded at baseline (before randomization) and at 2 and $6 \mathrm{~h}$ after randomization.

The use of accessory muscles was assessed according to the following scale: $0=$ no visible tonic or phasic use of neck muscles; $1=$ neck muscles taut but with no respira- 


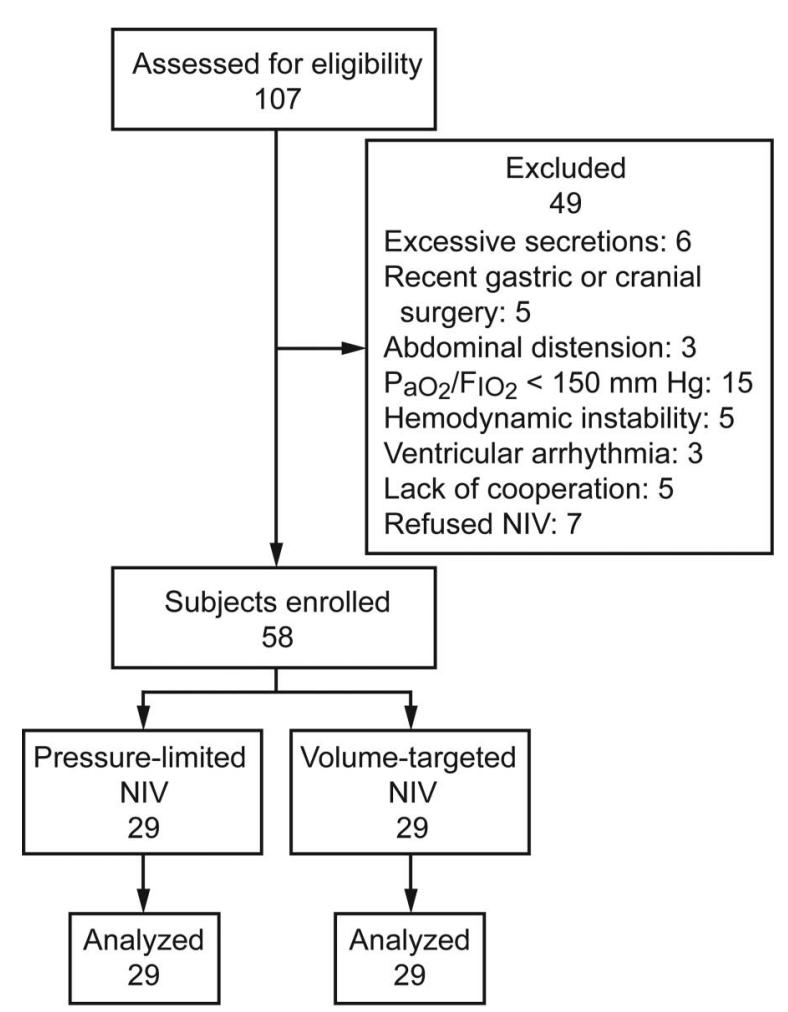

Fig. 1. Flow chart. NIV $=$ noninvasive ventilation.

tory modulation (ie, tonic activity); $2=$ mild respiratory modulation in neck muscle contraction; $3=$ moderate phasic activity (no supraclavicular or intercostal in-drawing); $4=$ vigorous phasic activity with in-drawing; $5=$ vigorous phasic activity with abdominal paradox. ${ }^{34}$ For the determination of $\mathrm{P}_{\mathrm{aO}_{2}} / \mathrm{F}_{\mathrm{IO}_{2}}$ while subjects were receiving NIV, $\mathrm{F}_{\mathrm{IO}_{2}}$ was calculated by using the following conversion factor: $21 \%+(3 \% \times$ oxygen flow in $\mathrm{L} / \mathrm{min}$ of supplemental oxygen). This conversion factor provides an approximation of percent oxygen delivered, is influenced by minute ventilation and breathing patterns, and may be inaccurate when air leakage occurs around the mask or through the mouth. ${ }^{35}$

All NIV parameters were continuously monitored by the built-in pneumotachograph and downloaded by ventilator software. Peak inspiratory pressure (PIP), EPAP, exhaled $\mathrm{V}_{\mathrm{T}}$, exhaled minute volume $\left(\dot{\mathrm{V}}_{\mathrm{E}}\right)$, and leak were recorded at 0,2 , and $6 \mathrm{~h}$ after randomization and were averaged over $5 \mathrm{~min}$ after the respective time points. The $\mathrm{SD}$ of $\mathrm{V}_{\mathrm{T}}$ and IPAP during the first $6 \mathrm{~h}$ for each subject, indicating individual variance, was produced by continuously monitored data. The daily use of NIV during the first $5 \mathrm{~d}$ after randomization was recorded using ventilator software.

The primary end point was the decrement of $\mathrm{P}_{\mathrm{aCO}_{2}}$ from baseline to $6 \mathrm{~h}$ after randomization. Secondary end points included the decrement of $\mathrm{P}_{\mathrm{aCO}}$ from baseline to $2 \mathrm{~h}$ after
Table 1. Subject Demographic and Baseline Characteristics

\begin{tabular}{|c|c|c|}
\hline Variable & $\begin{array}{l}\text { VT-NIV } \\
(n=29)\end{array}$ & $\begin{array}{l}\text { PL-NIV } \\
(n=29)\end{array}$ \\
\hline \multicolumn{3}{|l|}{ Demographics } \\
\hline Male sex, $n(\%)$ & $13(44.8)$ & $14(48.3)$ \\
\hline Age, mean $\pm \mathrm{SD}$ y & $73.9 \pm 10.0$ & $74.1 \pm 8.5$ \\
\hline Height, mean $\pm \mathrm{SD} \mathrm{cm}$ & $161.0 \pm 5.3$ & $161.5 \pm 8.2$ \\
\hline $\begin{array}{l}\text { Predicted body weight, } \\
\text { mean } \pm \text { SD kg }\end{array}$ & $55.8 \pm 6.2$ & $56.3 \pm 9.1$ \\
\hline \multicolumn{3}{|l|}{ Underlying diseases, $n(\%)$} \\
\hline COPD & $22(75.9)$ & $23(79.3)$ \\
\hline Asthma & $2(6.9)$ & $1(3.4)$ \\
\hline Bronchiectasis & $2(6.9)$ & $2(6.9)$ \\
\hline OSAS & $2(6.9)$ & $2(6.9)$ \\
\hline Other & $1(3.4)$ & $1(3.4)$ \\
\hline \multicolumn{3}{|l|}{ Vital signs, mean $\pm \mathrm{SD}$} \\
\hline Breathing frequency, breaths/min & $21.8 \pm 4.0$ & $23.0 \pm 5.4$ \\
\hline Scale for accessory muscle use & $3.6 \pm 1.1$ & $3.6 \pm 1.0$ \\
\hline $\mathrm{S}_{\mathrm{pO}_{2}}, \%$ & $88.0 \pm 8.3$ & $89.2 \pm 6.8$ \\
\hline Heart rate, beats/min & $85.8 \pm 12.4$ & $90.9 \pm 13.6$ \\
\hline $\mathrm{SBP}, \mathrm{mm} \mathrm{Hg}$ & $126.7 \pm 19.3$ & $130.3 \pm 20.1$ \\
\hline $\mathrm{DBP}, \mathrm{mm} \mathrm{Hg}$ & $69.5 \pm 8.9$ & $73.8 \pm 14.6$ \\
\hline \multicolumn{3}{|l|}{ Arterial blood gas, mean $\pm \mathrm{SD}$} \\
\hline $\mathrm{pH}$ & $7.29 \pm 0.03$ & $7.30 \pm 0.03$ \\
\hline $\mathrm{P}_{\mathrm{aCO}_{2}}, \mathrm{~mm} \mathrm{Hg}$ & $80.2 \pm 10.4$ & $76.4 \pm 12.7$ \\
\hline $\mathrm{P}_{\mathrm{aO}_{2}} / \mathrm{F}_{\mathrm{IO}_{2}}, \mathrm{~mm} \mathrm{Hg}$ & $216.0 \pm 62.9$ & $233.2 \pm 62.5$ \\
\hline $\mathrm{HCO}_{3}^{-}, \mathrm{mmol} / \mathrm{L}$ & $38.4 \pm 5.4$ & $36.4 \pm 4.6$ \\
\hline Previous use of NIV, $n(\%)$ & $5(17.2)$ & $2(6.9)$ \\
\hline $\begin{array}{l}\text { PL-NIV = pressure-limited noninvasive ventilati } \\
\text { VT-NIV = volume-targeted noninvasive ventilati } \\
\text { OSAS = obstructive sleep apnea syndrome } \\
\text { SBP = systolic blood pressure } \\
\text { DBP = diastolic blood pressure } \\
\mathrm{HCO}_{3}^{-}=\text {arterial bicarbonate concentration } \\
\text { NIV = noninvasive ventilation }\end{array}$ & & \\
\hline
\end{tabular}

randomization as well as outcomes of subjects (need for intubation, actual intubation rate, duration of NIV, weaning success rate of NIV, intolerance rate of NIV, 28-d mortality, in-hospital mortality, length of hospital stay, and hospital costs). Subjects were followed up until death, hospital discharge, or $28 \mathrm{~d}$ after randomization for subjects discharged home before day 28 .

\section{Statistical Analysis}

We expected that the decrement of $\mathrm{P}_{\mathrm{aCO}_{2}}$ from baseline to $6 \mathrm{~h}$ after randomization would be $10 \mathrm{~mm} \mathrm{Hg}$ in the PL-NIV group, based on our previous clinical experience with subjects meeting eligibility criteria. Based on the assumption that the decrement of $\mathrm{P}_{\mathrm{aCO}_{2}}$ from baseline to $6 \mathrm{~h}$ after randomization would be $17.5 \mathrm{~mm} \mathrm{Hg}$ in the VT-NIV group and the SD would be $10 \mathrm{~mm} \mathrm{Hg}$ (equivalent to a coefficient of variation of 133\%), a sample of 29 subjects in each group would be required to detect a difference of 
Table 2. Ventilator Parameters

\begin{tabular}{|c|c|c|c|c|}
\hline Variable & Group & $0 \mathrm{~h}$ & $2 \mathrm{~h}$ & $6 \mathrm{~h}$ \\
\hline \multirow[t]{3}{*}{ PIP, $\mathrm{cm} \mathrm{H} \mathrm{H}_{2} \mathrm{O}$} & VT-NIV $(n)$ & $15.2 \pm 3.3(29)$ & $15.5 \pm 3.4(29)$ & $15.4 \pm 3.1(28)$ \\
\hline & PL-NIV $(n)$ & $15.3 \pm 3.1(29)$ & $16.2 \pm 3.1(29)$ & $16.6 \pm 3.1(29)$ \\
\hline & $P$ & .87 & .40 & .14 \\
\hline \multirow[t]{3}{*}{ EPAP, $\mathrm{cm} \mathrm{H}_{2} \mathrm{O}$} & VT-NIV $(n)$ & $6.3 \pm 1.0(29)$ & $6.3 \pm 1.0(29)$ & $6.4 \pm 1.0(28)$ \\
\hline & PL-NIV $(n)$ & $6.4 \pm 1.0(29)$ & $6.4 \pm 1.0(29)$ & $6.4 \pm 1.0(29)$ \\
\hline & $P$ & .79 & .60 & .93 \\
\hline \multirow[t]{3}{*}{ Exhaled $\mathrm{V}_{\mathrm{T}}, \mathrm{mL}$} & VT-NIV $(n)$ & $563.0 \pm 84.4(29)$ & $568.8 \pm 63.6(29)$ & $582.6 \pm 70.0(28)$ \\
\hline & PL-NIV $(n)$ & $536.9 \pm 133.5(29)$ & $550.8 \pm 115.8(29)$ & $581.4 \pm 132.3(29)$ \\
\hline & $P$ & .38 & .47 & .96 \\
\hline \multirow[t]{3}{*}{$\dot{\mathrm{V}}_{\mathrm{E}}, \mathrm{L} / \mathrm{min}$} & VT-NIV $(n)$ & $12.6 \pm 2.4(29)$ & $12.3 \pm 2.2(29)$ & $12.0 \pm 2.0(28)$ \\
\hline & PL-NIV $(n)$ & $12.3 \pm 4.2(29)$ & $11.8 \pm 4.2(29)$ & $12.0 \pm 2.9(29)$ \\
\hline & $P$ & .70 & .62 & .95 \\
\hline \multirow[t]{3}{*}{ Leak, L/min } & VT-NIV $(n)$ & $30.5 \pm 8.7(29)$ & $31.0 \pm 9.8(29)$ & $30.6 \pm 9.4(28)$ \\
\hline & PL-NIV $(n)$ & $31.3 \pm 8.2(29)$ & $29.2 \pm 9.5(29)$ & $29.8 \pm 7.3(29)$ \\
\hline & $P$ & .72 & .47 & .72 \\
\hline $\begin{array}{l}\text { Values are means } \pm \mathrm{SD} \\
\text { PIP }=\text { peak inspiratory } \\
\text { PL-NIV = pressure-limi } \\
\text { VT-NIV = volume-targ } \\
\text { EPAP = expiratory posi } \\
\mathrm{V}_{\mathrm{T}}=\text { tidal volume } \\
\mathrm{V}_{\mathrm{E}}=\text { minute volume }\end{array}$ & $\begin{array}{l}\text { n comparison betw } \\
\text { entilation } \\
\text { entilation } \\
\text { ire }\end{array}$ & the same time point. & & \\
\hline
\end{tabular}

$7.5 \mathrm{~mm} \mathrm{Hg}$ in the decrement of $\mathrm{P}_{\mathrm{aCO}}$ with $80 \%$ power and a 2-tailed $\alpha$ value of .05.

Continuous variables are presented as mean \pm SD with normal distribution or as median (interquartile range) with non-normal distribution unless otherwise specified. Qualitative or categorical variables are presented as absolute numbers with percentages. The test of normality was performed using the Kolmogorov-Smirnov test, and the homogeneity of variances was performed using the Levene test. Continuous variables between the 2 groups were compared using the Student $t$ test for variables with a normal distribution and the Mann-Whitney $U$ test for variables with a non-normal distribution. Variables within the same group were compared using analysis of variance for repeated measures, and the Bonferroni adjustment for multiplicity of tests was applied for post hoc comparisons to ensure that the total error rate did not exceed 0.05. Qualitative or categorical variables were compared by a chisquare test with or without continuity correction. The Kaplan-Meier estimate-of-survival curve was used to determine the following within $28 \mathrm{~d}$ after randomization: the cumulative incidence of intubation, the cumulative probability of remaining on NIV, and the cumulative probability of survival. Curves between the 2 groups were compared using the log-rank test. All tests were 2-sided. Differences with $P$ values of $<.05$ were considered statistically significant, except for those from multiple comparisons. Statistical analysis was performed with SPSS 19.0 (SPSS, Chicago, Illinois).

\section{Results}

\section{Subjects}

From January 2013 through December 2013, a total of 107 patients with AHRF were eligible for inclusion in the study, and 58 underwent randomization. A total of 29 subjects were assigned to the PL-NIV group and 29 to the VT-NIV group, and all of these subjects were included in the analysis (Fig. 1).

The demographic and baseline characteristics of the subjects at entry into the study were similar in both groups (Table 1). There was no statistically significant difference in baseline $\mathrm{P}_{\mathrm{aCO}_{2}}$ between the 2 groups $(P=.22$; Table 1$)$.

\section{NIV Application}

In subjects receiving VT-NIV, the preset target $\mathrm{V}_{\mathrm{T}}$ was $558.0 \pm 62.0 \mathrm{~mL}$. PIP, EPAP, exhaled $\mathrm{V}_{\mathrm{T}}, \dot{\mathrm{V}}_{\mathrm{E}}$, and leak at 0,2 , and $6 \mathrm{~h}$ did not differ significantly between the 2 groups $(P>.05$; Table 2). During the first $6 \mathrm{~h}$, the variance of $\mathrm{V}_{\mathrm{T}}$ was significantly lower in the VT-NIV group, as indicated by its lower individual SD $(P<.001$; Fig. 2$)$. In contrast, the variance of PIP was significantly higher in the VT-NIV group, also as indicated by its higher individual SD $(P<.001$; Fig. 2). There was no difference in mean daily use of NIV during the first $5 \mathrm{~d}$ between the 2 groups $(P>.05$; Fig. 3$)$. 

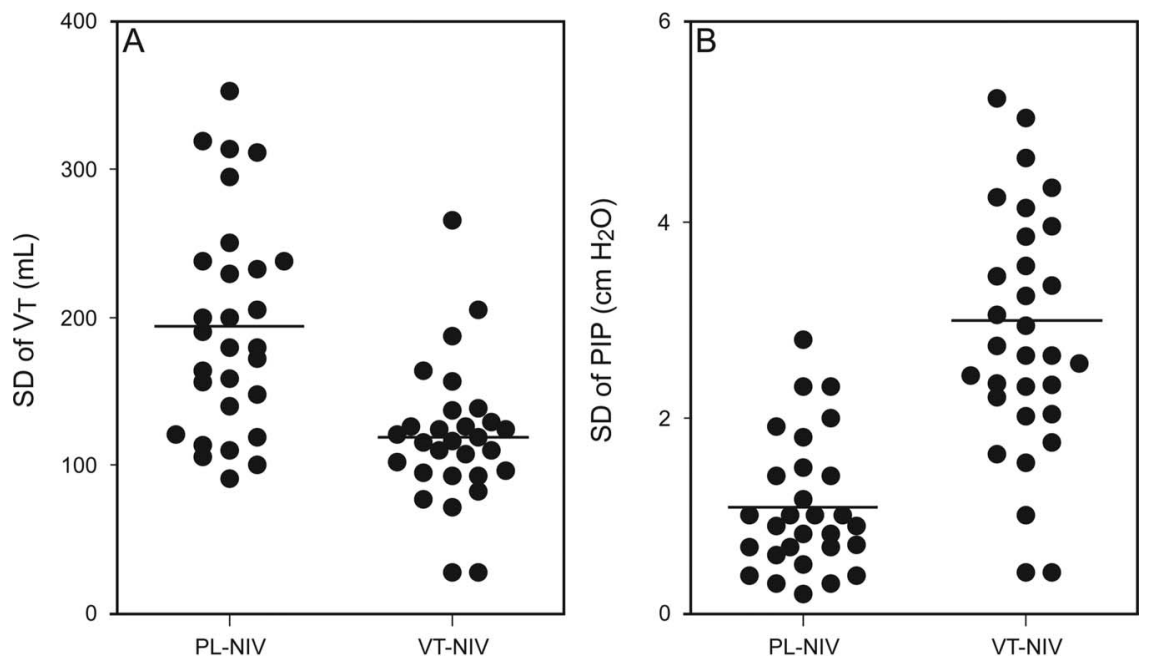

Fig. 2. SD of tidal volume $(A)$ and peak inspiratory pressure $(B)$ during the first $6 \mathrm{~h}$ after randomization. Points denote individual values and horizontal lines denote means. In both panels, $P<.001$ between the pressure-limited noninvasive ventilation group (PL-NIV) and volumetargeted noninvasive ventilation group (VT-NIV).

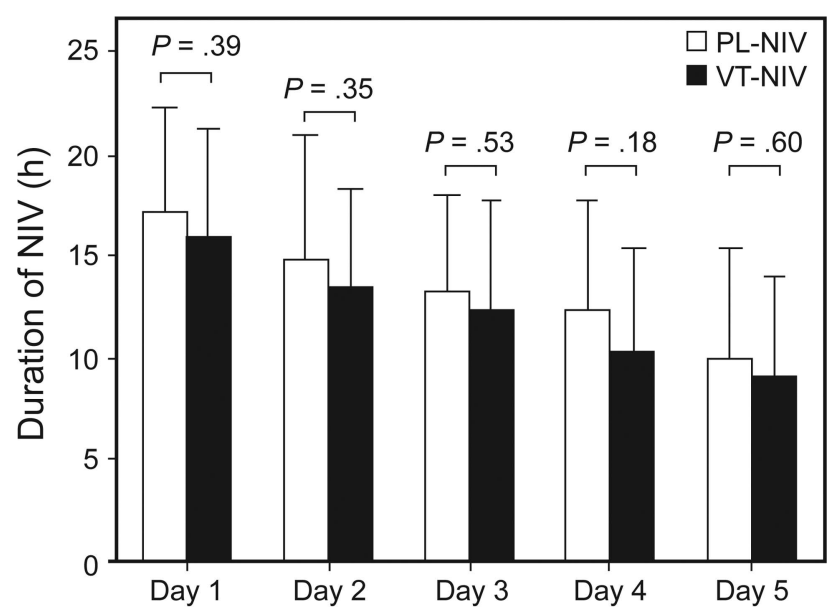

Fig. 3. Daily use of noninvasive ventilation during the first $5 \mathrm{~d}$ after randomization. Values are given as means, and error bars denote SD. PL-NIV = pressure-limited noninvasive ventilation; VT-NIV = volume-targeted noninvasive ventilation.

\section{Physiological Measurements}

As shown in Figure 4A, the primary end point, the decrement of $\mathrm{P}_{\mathrm{aCO}}$ from baseline to $6 \mathrm{~h}$ after randomization, was not statistically different between the PL-NIV group and the VT-NIV group $(9.3 \pm 12.6 \mathrm{~mm} \mathrm{Hg}$ vs $11.7 \pm 12.9 \mathrm{~mm} \mathrm{Hg}, P=.48)$. In addition, there was no difference in the decrement of $\mathrm{P}_{\mathrm{aCO}}$ from baseline to $2 \mathrm{~h}$ after randomization between the PL-NIV group and the VT-NIV group $(6.4 \pm 12.7 \mathrm{~mm} \mathrm{Hg}$ vs $5.0 \pm 15.8 \mathrm{~mm} \mathrm{Hg}$, $P=.71)$ (Fig. 4B).

In both groups, there were significant and comparable within-group improvements over the first $6 \mathrm{~h}$ in scale for accessory muscle use, arterial $\mathrm{pH}$, and $\mathrm{P}_{\mathrm{aCO}_{2}}(P<.05$; Fig.
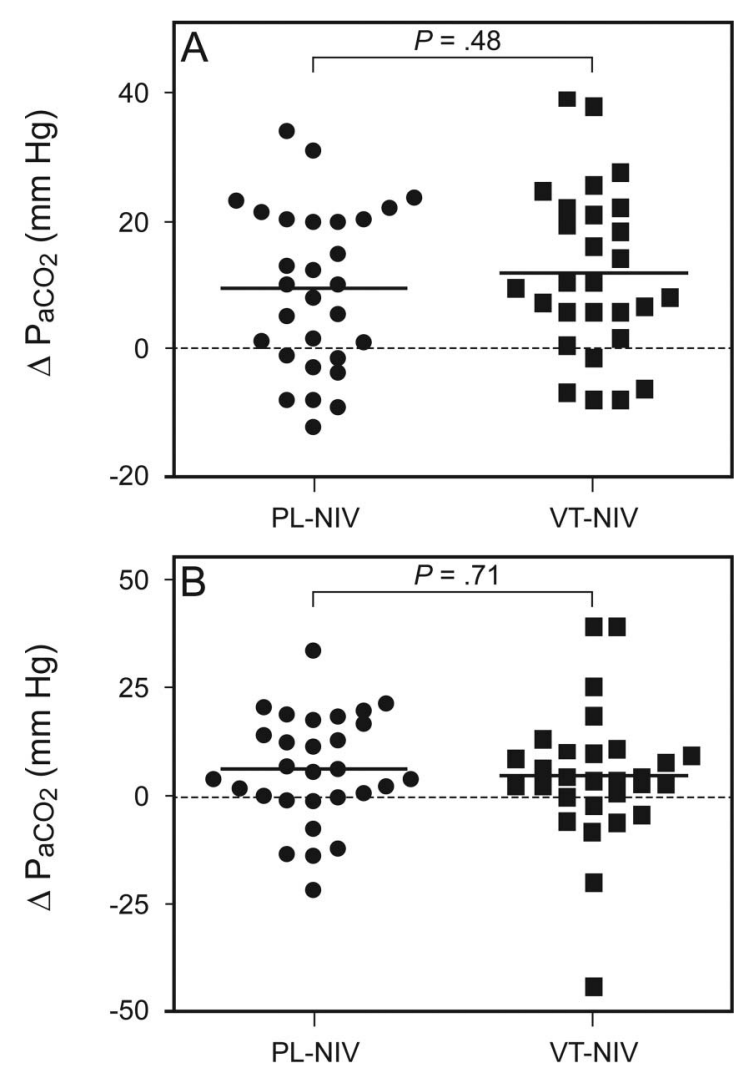

Fig. 4. Decrement of $\mathrm{P}_{\mathrm{aCO}}$ from baseline to $6 \mathrm{~h}$ after randomization (A) and from baseline to $2 \mathrm{~h}$ after randomization (B). Points denote individual values, and solid horizontal lines denote means. PL-NIV = pressure-limited noninvasive ventilation; VT-NIV $=$ volume-targeted noninvasive ventilation.

5, A, D, and E). Breathing frequency did not change significantly in the VT-NIV group, decreasing significantly only at $5 \mathrm{~h}$ in the PL-NIV group (Fig. 5B). $\mathrm{S}_{\mathrm{pO}_{2}}$ 

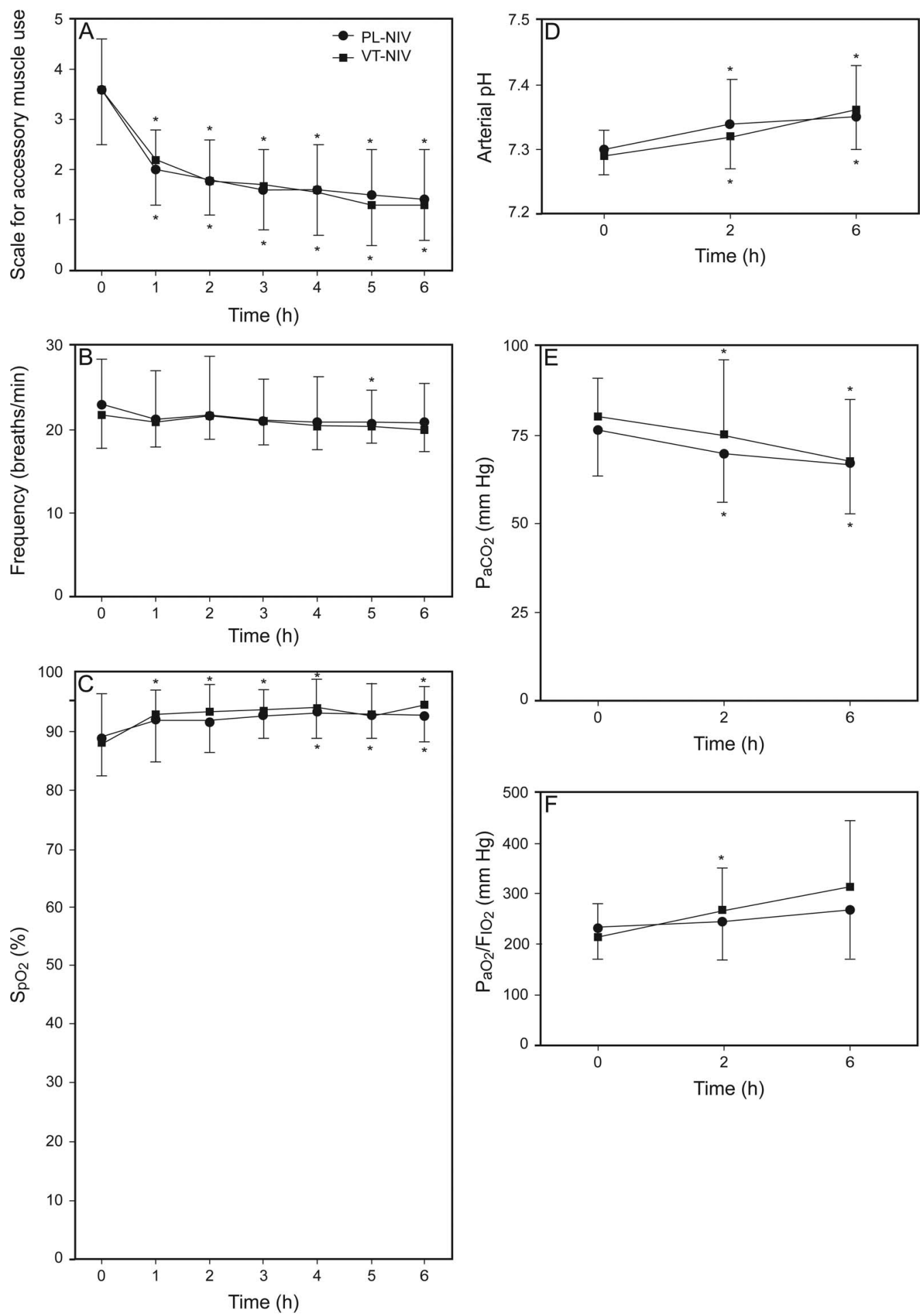

Fig. 5. Scale for accessory muscle use (A), breathing frequency (B), $\mathrm{S}_{\mathrm{pO}_{2}}(\mathrm{C})$, arterial pH $(\mathrm{D}), \mathrm{P}_{\mathrm{acO}_{2}}(\mathrm{E})$, and $\mathrm{P}_{\mathrm{aO}} / \mathrm{F}_{1 \mathrm{O}_{2}}(\mathrm{~F})$ at baseline $(0 \mathrm{~h})$ and after randomization in subjects receiving pressure-limited noninvasive ventilation (PL-NIV) and volume-targeted noninvasive ventilation (VT-NIV). Values are given as mean $\pm \mathrm{SD} .{ }^{*}, P<.05$ compared with baseline within the same group.

significantly improved over time in the VT-NIV group and began to improve only at $4 \mathrm{~h}$ in the PL-NIV group (Fig. 5C). $\mathrm{P}_{\mathrm{aO}_{2}} / \mathrm{F}_{\mathrm{IO}_{2}}$ significantly improved over time in the VT-NIV group and only tended to improve in the PL-NIV group (Fig. 5F). There were no between-group differences concerning $\mathrm{P}_{\mathrm{aCO}}$ or any of the other phys- 
Table 3. Clinical Outcomes

\begin{tabular}{|c|c|c|c|}
\hline Variable & PL-NIV $(n=29)$ & VT-NIV $(n=29)$ & $P$ \\
\hline Need for intubation, $n(\%)$ & $5(17.2)$ & $3(10.3)$ & .70 \\
\hline Intubation, $n(\%)$ & $5(17.2)$ & $3(10.3)$ & .70 \\
\hline Duration of NIV, median (IQR) d & $6.0(4.0-9.5)$ & $9.0(4.0-13.0)$ & .19 \\
\hline NIV intolerance, $n(\%)$ & $3(10.3)$ & $5(17.2)$ & .70 \\
\hline Weaning success of NIV, $n(\%)$ & $15(51.7)$ & $13(44.8)$ & .60 \\
\hline Death at day $28, n(\%)$ & $3(10.3)$ & $2(6.9)$ & $>.99$ \\
\hline Death in hospital, $n(\%)$ & $3(10.3)$ & $2(6.9)$ & $>.99$ \\
\hline Length of hospital stay, mean $\pm \mathrm{SD} d$ & $12.8 \pm 9.9$ & $14.1 \pm 10.3$ & 62 \\
\hline Hospital costs, median (IQR) $\$$ & $2,749.30(2,057.00-3,566.40)$ & $2,796.50(1,446.10-4,347.80)$ & .85 \\
\hline $\begin{array}{l}\text { PL-NIV, pressure-limited noninvasive ventilation } \\
\text { VT-NIV, volume-targeted noninvasive ventilation } \\
\text { NIV, noninvasive ventilation } \\
\text { IQR = interquartile range }\end{array}$ & & & \\
\hline
\end{tabular}

iological parameters at any of the prespecified time points $(P>.05$; Fig. 5).

\section{Clinical Outcomes}

The clinical outcomes of all of the subjects are shown in Table 3. There were no statistically significant differences in the need for intubation and the actual intubation rate between the 2 groups $(P>.05)$. Likewise, the cumulative incidence of intubation within $28 \mathrm{~d}$ after randomization did not differ significantly between the 2 groups $(P=.49$ by log-rank test; Fig. 6A). There were no statistically significant differences in duration of NIV, intolerance rate of NIV, and NIV weaning success rate between the 2 groups $(P>.05)$. The cumulative probability of remaining on NIV within $28 \mathrm{~d}$ after randomization did not differ significantly between the 2 groups $(P=.40$ by log-rank test; Fig. 6B). There were no statistically significant differences in the 28-d mortality and in-hospital mortality between the 2 groups, and the cumulative survival probability within $28 \mathrm{~d}$ after randomization did not differ significantly between the 2 groups ( $P=.62$ by log-rank test; Fig. $6 \mathrm{C})$. No significant differences were observed in the length of hospital stay and hospital costs between the 2 groups $(P>.05)$.

\section{Discussion}

To the best of our knowledge, the present study is the first randomized controlled trial to perform VT-NIV in subjects with AHRF. The main finding of this study is that VT-NIV was as effective as PL-NIV in correcting hypercapnia, reducing the need for intubation, and improving survival in subjects with AHRF.

Our aim was to compare the effectiveness of VT-NIV and PL-NIV in subjects with AHRF. It is well known that PL-NIV in subjects with AHRF increases $\dot{V}_{E}$ by increas- ing $\mathrm{V}_{\mathrm{T}}$ and allowing frequency to fall, thus improving $\mathrm{P}_{\mathrm{aCO}_{2}}{ }^{6.36}$ However, during PL-NIV, fixed-level pressure support is provided by the ventilator, and the delivered $\mathrm{V}_{\mathrm{T}}$ cannot be guaranteed: It varies, depending on inspiratory effort, airway resistance, and chest-wall and lung compliance. ${ }^{24,25}$ Conceivably, $\mathrm{P}_{\mathrm{aCO}_{2}}$ may not be efficiently improved in some subjects, particularly in subjects with AHRF. By contrast, VT-NIV can guarantee a relatively constant $\mathrm{V}_{\mathrm{T}}$, with a preset target $\mathrm{V}_{\mathrm{T}}$ and a pressure support adjusted automatically within a preset range to provide a $\mathrm{V}_{\mathrm{T}}$ as close as possible to the target $\mathrm{V}_{\mathrm{T}} \cdot{ }^{24,26}$ Therefore, in subjects with AHRF, it is possible that VT-NIV would lead to a more pronounced improvement in $\mathrm{P}_{\mathrm{aCO}_{2}}$ than PL-NIV.

Consistent with findings from previous studies ${ }^{6,10}$ and meta-analyses, ${ }^{11,12} \mathrm{P}_{\mathrm{aCO}_{2}}$ was significantly improved after PL-NIV use. However, we found no more pronounced improvement in $\mathrm{P}_{\mathrm{aCO}_{2}}$ from baseline to $6 \mathrm{~h}$ and to $2 \mathrm{~h}$ after randomization in VT-NIV, and $\mathrm{P}_{\mathrm{aCO}_{2}}$ improved comparably 2-6 h after randomization in both groups. In contrast, Briones Claudett et $\mathrm{al}^{32}$ reported a case-control study that assessed the efficacy of VT-NIV in 22 subjects with AHRF, observing that $1-12 \mathrm{~h}$ after randomization, $\mathrm{P}_{\mathrm{aCO}_{2}}$ improved more significantly in VT-NIV than in PL-NIV. A possible explanation of the difference in results between the 2 studies is that PIP, $\mathrm{V}_{\mathrm{T}}$, and $\dot{\mathrm{V}}_{\mathrm{E}}$ were obviously higher in VTNIV than in PL-NIV in the study of Briones Claudett et $\mathrm{al},{ }^{32}$ whereas these variables were not significantly different between the 2 groups in the present study.

In line with our study, Murphy et $\mathrm{a}^{28}$ demonstrated that in subjects with obesity hypoventilation syndrome, daytime $\mathrm{P}_{\mathrm{aCO}}$ improved similarly between the 2 modes, and Crisafulli et $\mathrm{al}^{30}$ also demonstrated that in subjects with stable hypercapnic COPD, $\mathrm{P}_{\mathrm{aCO}_{2}}$ improved comparably in both modes, with similar IPAP delivered in both modes. Nevertheless, Storre et $\mathrm{al}^{27}$ and Janssens 

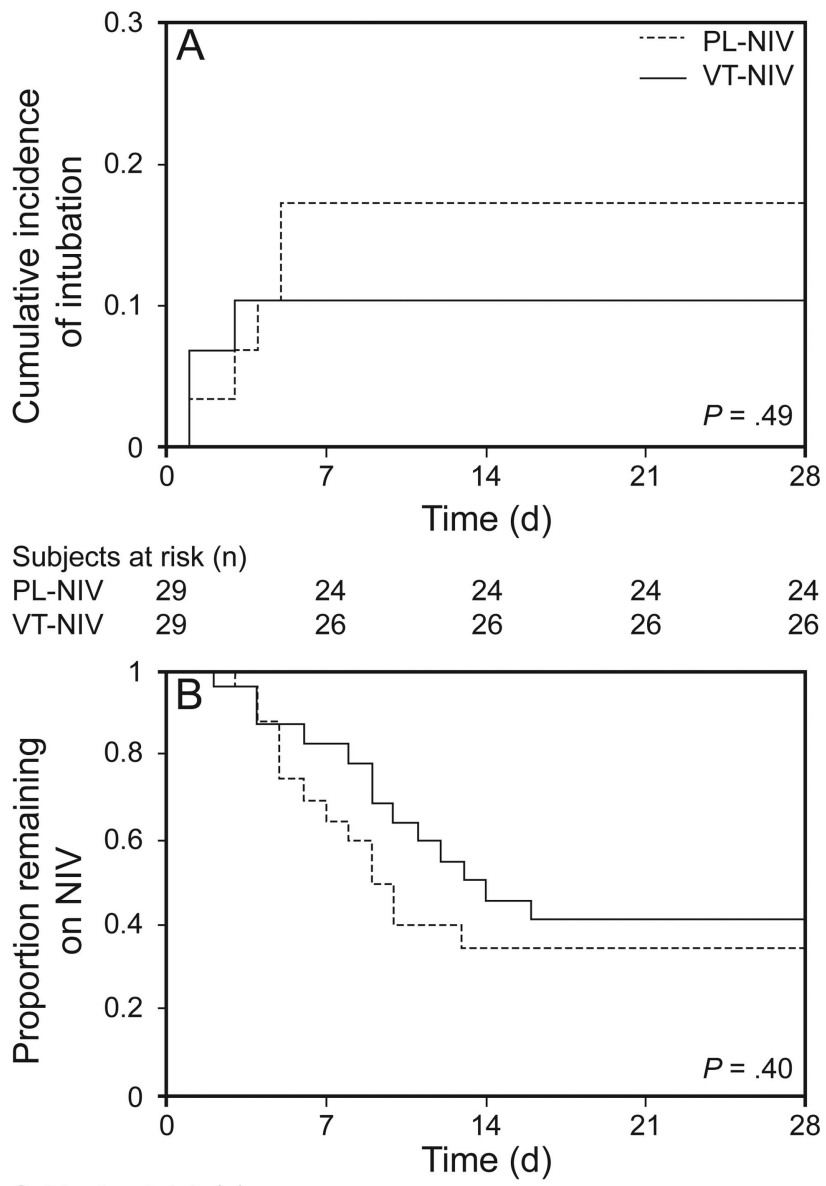

$\begin{array}{llllll}\text { Subjects at risk }(\mathrm{n}) & & & & \\ \text { PL-NIV } & 29 & 13 & 7 & 7 & 7 \\ \text { VT-NIV } & 29 & 18 & 10 & 9 & 9\end{array}$

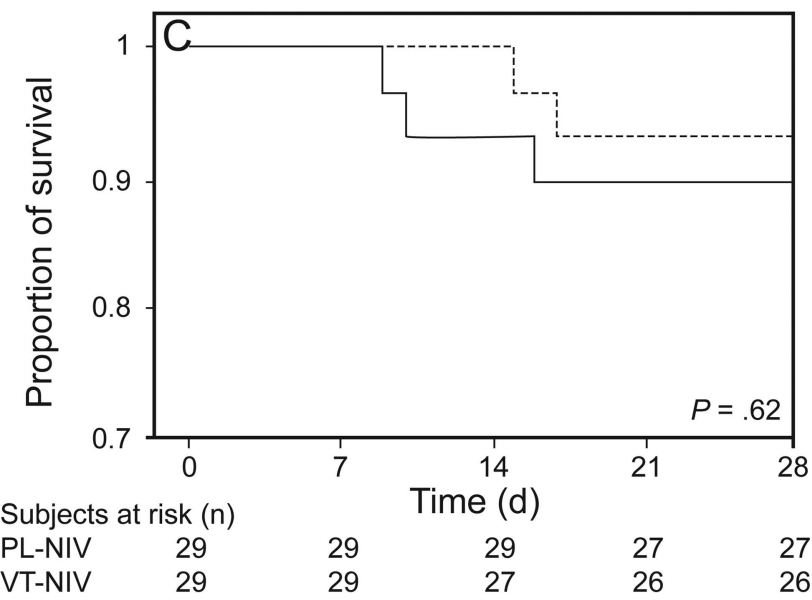

Fig. 6. Kaplan-Meier plot of the cumulative incidence of intubation (A), the cumulative probability of remaining on noninvasive ventilation (B), and the cumulative probability of survival (C) within $28 \mathrm{~d}$ after randomization. PL-NIV = pressure-limited noninvasive ventilation; VT-NIV = volume-targeted noninvasive ventilation. $P$ values are by log-rank test. et $\mathrm{al}^{26}$ reported that in subjects with obesity hypoventilation syndrome, mean transcutaneous $\mathrm{P}_{\mathrm{aCO}}$ improved significantly more in VT-NIV than in PL-NIV, whereas PIP and delivered IPAP in VT-NIV were higher than in PL-NIV. In addition, Storre et $\mathrm{al}^{31}$ found that although high-intensity NIV was performed to be compared with VT-NIV in subjects with chronic hypercapnic COPD, there remained no difference in the improvement of $\mathrm{P}_{\mathrm{aCO}_{2}}$, with similar PIP and $\mathrm{V}_{\mathrm{T}}$ being delivered. Therefore, $\mathrm{P}_{\mathrm{aCO}_{2}}$ was comparably improved in our study, possibly because in VT-NIV, the target $\mathrm{V}_{\mathrm{T}}$ that we preset in our protocol was $10 \mathrm{~mL} / \mathrm{kg}$, whereas in PL-NIV, the aim of the adjustment of IPAP by the clinician was also to obtain a $\mathrm{V}_{\mathrm{T}}$ of $8-10 \mathrm{~mL} / \mathrm{kg}$; consequently, a comparable pressure support level was delivered, and similar $\mathrm{V}_{\mathrm{T}}$ and $\dot{\mathrm{V}}_{\mathrm{E}}$ were produced.

As expected, we found that in VT-NIV, the variance of $\mathrm{V}_{\mathrm{T}}$ was significantly lower, with a lower individual SD for each subject, suggesting that the delivered $V_{T}$ was more constant, and we also found that the actual $\mathrm{V}_{\mathrm{T}}$ was very close to the target $\mathrm{V}_{\mathrm{T}}$ in VT-NIV. However, on the basis of a similar pressure support level and delivered $\mathrm{V}_{\mathrm{T}}$ in both modes, VT-NIV did not lead to more pronounced improvement in $\mathrm{P}_{\mathrm{aCO}}$, at least over the first $6 \mathrm{~h}$. Hence, keeping the delivered $\mathrm{V}_{\mathrm{T}}$ constant and close to the target value may not be responsible for the improvement in $\mathrm{P}_{\mathrm{aCO}_{2}}$; the pressure support level and $\mathrm{V}_{\mathrm{T}}$ value are more likely to play a key role in the improvement in $\mathrm{P}_{\mathrm{aCO}_{2}}$.

In accordance with the findings of previous studies ${ }^{6-9}$ and a meta-analysis, ${ }^{12}$ in which $6.7-25.6 \%$ of subjects needed intubation, we found that $17.2 \%$ of subjects in the PL-NIV group needed intubation. Furthermore, we found no difference in the need for intubation between the 2 modes. Two reasons may explain the similar efficacy of the 2 modes in the need for intubation. First, vital signs and arterial blood gases (especially $\mathrm{pH}$ and $\mathrm{P}_{\mathrm{aCO}_{2}}$ ) were comparably improved in both groups, suggesting comparable improvement of respiratory failure in both groups. Second, no difference was observed in the mean daily use of NIV during the first $5 \mathrm{~d}$ and the intolerance rate of NIV between the 2 groups, which indicated that subjects' comfort in the 2 modes was similar. It is of importance to note that NIV was terminated on the presence of NIV intolerance, regardless of the improvement in respiratory failure, and subjects were intubated when the hypercapnic respiratory failure progressively worsened after termination of NIV; thus, a similar NIV intolerance rate may lead to a similar need for intubation.

In line with the mortality of $9.3-10.2 \%$ shown in previous studies, ${ }^{6,7}$ in-hospital mortality was $10.3 \%$ in our study. Furthermore, we found no difference in in-hospital mortality between the 2 modes. Possible factors that may explain these findings are that there was no difference in baseline characteristics between the 2 groups, and the in- 


\section{Volume-Targeted vs Pressure-Limited NIV in AHRF}

tubation rate was similar, suggesting that the improvement of the subject's clinical condition and respiratory failure may be similar, and the incidence of serious complications related to invasive ventilation (eg, ventilator-induced lung injury, ventilator-associated pneumonia) that are able to increase mortality may be no different between the 2 groups. ${ }^{37,38}$

Several limitations of this study should be taken into account. First, it is impossible to strictly blind the investigators and attending physicians in this type of open clinical trial, which may lead to possible bias. Despite the fact that we predefined criteria for all relevant interventions, clinical decisions, and outcome variables, such bias could not be entirely controlled. Second, the sample size is not large, which may lead to a low power of detection of significant between-group differences in the decrement of $\mathrm{P}_{\mathrm{aCO}}$; however, the planned sample size was achieved, and to the best of our knowledge, this is the largest clinical study to date on VT-NIV. Third, $\mathrm{P}_{\mathrm{aCO}_{2}}$ was comparably improved in both modes, possibly because the target $\mathrm{V}_{\mathrm{T}}$ was similar, so that actual pressure support level and $V_{T}$ were comparably produced. However, in cases where target $\mathrm{V}_{\mathrm{T}}$ in VT-NIV differs from PL-NIV, it is possible that VT-NIV would lead to a different improvement in $\mathrm{P}_{\mathrm{aCO}}$. Fourth, this study was performed in subjects with AHRF with arterial $\mathrm{pH}<7.35$ and $\geq 7.25$, suggesting that the results may not be generalizable to AHRF subjects with arterial $\mathrm{pH}<7.25$ or $\geq 7.35$. Finally, this study was undertaken at 8 hospital units with a great deal of experience with NIV use, suggesting that the results may not be generalizable to units without such experience.

\section{Conclusions}

Our study indicates that regardless of whether a VT- or PL-NIV strategy is employed, it is possible to provide similar support to patients with AHRF, and we suggest that VT-NIV may be considered as an alternative to PLNIV in such patients.

\section{ACKNOWLEDGMENTS}

We thank Dr Yichong Li for help in performing the statistical analysis.

\section{REFERENCES}

1. Chandra D, Stamm JA, Taylor B, Ramos RM, Satterwhite L, Krishnan JA, et al. Outcomes of noninvasive ventilation for acute exacerbations of chronic obstructive pulmonary disease in the United States, 1998-2008. Am J Respir Crit Care Med 2012;185(2):152159.

2. Cabrini L, Esquinas A, Pasin L, Nardelli P, Frati E, Pintaudi M, et al. An international survey on noninvasive ventilation use for acute respiratory failure in general non-monitored wards. Respir Care 2015; 60(4):586-592.

3. Stefan MS, Shieh MS, Pekow PS, Rothberg MB, Steingrub JS, Lagu T, Lindenauer PK. Epidemiology and outcomes of acute respiratory failure in the United States, 2001 to 2009: a national survey. J Hosp Med 2013;8(2):76-82.

4. Walkey AJ, Wiener RS. Use of noninvasive ventilation in patients with acute respiratory failure, 2000-2009: a population-based study. Ann Am Thorac Soc 2013;10(1):10-17.

5. Esteban A, Frutos-Vivar F, Muriel A, Ferguson ND, Peñuelas O, Abraira V, et al. Evolution of mortality over time in patients receiving mechanical ventilation. Am J Respir Crit Care Med 2013;188(2): 220-230.

6. Plant PK, Owen JL, Elliott MW. Early use of non-invasive ventilation for acute exacerbations of chronic obstructive pulmonary disease on general respiratory wards: a multicentre randomised controlled trial. Lancet 2000;355(9219):1931-1935.

7. Brochard L, Mancebo J, Wysocki M, Lofaso F, Conti G, Rauss A, et al. Noninvasive ventilation for acute exacerbations of chronic obstructive pulmonary disease. N Engl J Med 1995;333(13):817-822.

8. Kramer N, Meyer TJ, Meharg J, Cece RD, Hill NS. Randomized, prospective trial of noninvasive positive pressure ventilation in acute respiratory failure. Am J Respir Crit Care Med 1995;151(6):17991806.

9. Celikel T, Sungur M, Ceyhan B, Karakurt S. Comparison of noninvasive positive pressure ventilation with standard medical therapy in hypercapnic acute respiratory failure. Chest 1998;114(6):1636-1642.

10. Collaborative Research Group of Noninvasive Mechanical Ventilation for Chronic Obstructive Pulmonary Disease. Early use of noninvasive positive pressure ventilation for acute exacerbations of chronic obstructive pulmonary disease: a multicentre randomized controlled trial. Chin Med J 2005;118(24):2034-2040.

11. Lightowler JV, Wedzicha JA, Elliott MW, Ram FS. Non-invasive positive pressure ventilation to treat respiratory failure resulting from exacerbations of chronic obstructive pulmonary disease: Cochrane systematic review and meta-analysis. BMJ 2003;326(7382):185.

12. Ram FS, Picot J, Lightowler J, Wedzicha JA. Non-invasive positive pressure ventilation for treatment of respiratory failure due to exacerbations of chronic obstructive pulmonary disease. Cochrane Database Syst Rev 2004(3):CD004104.

13. Peter JV, Moran JL, Phillips-Hughes J, Graham P, Bersten AD. Effect of non-invasive positive pressure ventilation (NIPPV) on mortality in patients with acute cardiogenic pulmonary oedema: a metaanalysis. Lancet 2006;367(9517):1155-1163.

14. Weng CL, Zhao YT, Liu QH, Fu CJ, Sun F, Ma YL, et al. Metaanalysis: noninvasive ventilation in acute cardiogenic pulmonary edema. Ann Intern Med 2010;152(9):590-600.

15. Park M, Sangean MC, Volpe Mde S, Feltrim MI, Nozawa E, Leite $\mathrm{PF}$, et al. Randomized, prospective trial of oxygen, continuous positive airway pressure, and bilevel positive airway pressure by face mask in acute cardiogenic pulmonary edema. Crit Care Med 2004; 32(12):2407-2415

16. Masip J, Betbesé AJ, Páez J, Vecilla F, Cañizares R, Padró J, et al. Non-invasive pressure support ventilation versus conventional oxygen therapy in acute cardiogenic pulmonary oedema: a randomised trial. Lancet 2000;356(9248):2126-2132.

17. Antonelli M, Conti G, Bufi M, Costa MG, Lappa A, Rocco M, et al. Noninvasive ventilation for treatment of acute respiratory failure in patients undergoing solid organ transplantation: a randomized trial. JAMA 2000;283(2):235-241.

18. Hilbert G, Gruson D, Vargas F, Valentino R, Gbikpi-Benissan G, Dupon M, et al. Noninvasive ventilation in immunosuppressed patients with pulmonary infiltrates, fever, and acute respiratory failure. N Engl J Med 2001;344(7):481-487.

19. Nava S, Ambrosino N, Clini E, Prato M, Orlando G, Vitacca M, et al. Noninvasive mechanical ventilation in the weaning of patients with respiratory failure due to chronic obstructive pulmonary dis- 


\section{Volume-TARgeted vs Pressure-Limited NIV in AHRF}

ease. A randomized, controlled trial. Ann Intern Med 1998;128(9): 721-728.

20. Ferrer M, Esquinas A, Arancibia F, Bauer TT, Gonzalez G, Carrillo A, et al. Noninvasive ventilation during persistent weaning failure: a randomized controlled trial. Am J Respir Crit Care Med 2003;168(1): 70-76.

21. Collaborating Research Group for Noninvasive Mechanical Ventilation of Chinese Respiratory Society. Pulmonary infection control window in treatment of severe respiratory failure of chronic obstructive pulmonary diseases: a prospective, randomized controlled, multicentred study. Chin Med J 2005;118(19):1589-1594.

22. Hess DR. The evidence for noninvasive positive-pressure ventilation in the care of patients in acute respiratory failure: a systematic review of the literature. Respir Care 2004;49(7):810-829.

23. Lloyd-Owen SJ, Donaldson GC, Ambrosino N, Escarabill J, Farre R, Fauroux B, et al. Patterns of home mechanical ventilation use in Europe: results from the Eurovent survey. Eur Respir J 2005;25(6): 1025-1031.

24. Vrijsen B, Chatwin M, Contal O, Derom E, Janssens JP, Kampelmacher MJ, et al. Hot topics in noninvasive ventilation: report of a working group at the International Symposium on Sleep-Disordered Breathing in Leuven, Belgium. Respir Care 2015;60(9):1337-1362.

25. Tuggey JM, Elliott MW. Randomised crossover study of pressure and volume non-invasive ventilation in chest wall deformity. Thorax 2005;60(10):859-864

26. Janssens JP, Metzger M, Sforza E. Impact of volume targeting on efficacy of bi-level non-invasive ventilation and sleep in obesityhypoventilation. Respir Med 2009;103(2):165-172.

27. Storre JH, Seuthe B, Fiechter R, Milioglou S, Dreher M, Sorichter S, Windisch W. Average volume-assured pressure support in obesity hypoventilation: a randomized crossover trial. Chest 2006;130(3): 815-821.

28. Murphy PB, Davidson C, Hind MD, Simonds A, Williams AJ, Hopkinson NS, et al. Volume targeted versus pressure support noninvasive ventilation in patients with super obesity and chronic respiratory failure: a randomised controlled trial. Thorax 2012;67(8):727734
29. Ambrogio C, Lowman X, Kuo M, Malo J, Prasad AR, Parthasarathy S. Sleep and non-invasive ventilation in patients with chronic respiratory insufficiency. Intensive Care Med 2009;35(2):306-313.

30. Crisafulli E, Manni G, Kidonias M, Trianni L, Clini EM. Subjective sleep quality during average volume assured pressure support (AVAPS) ventilation in patients with hypercapnic COPD: a physiological pilot study. Lung 2009;187(5):299-305.

31. Storre JH, Matrosovich E, Ekkernkamp E, Walker DJ, Schmoor C, Dreher M, Windisch W. Home mechanical ventilation for COPD: high-intensity versus target volume noninvasive ventilation. Respir Care 2014;59(9):1389-1397.

32. Briones Claudett KH, Briones Claudett M, Chung Sang Wong M, Nuques Martinez A, Soto Espinoza R, Montalvo M, et al. Noninvasive mechanical ventilation with average volume assured pressure support (AVAPS) in patients with chronic obstructive pulmonary disease and hypercapnic encephalopathy. BMC Pulm Med 2013;13: 12.

33. Ferrer M, Valencia M, Nicolas JM, Bernadich O, Badia JR, Torres A. Early noninvasive ventilation averts extubation failure in patients at risk: a randomized trial. Am J Respir Crit Care Med 2006;173(2): 164-170.

34. Patrick W, Webster K, Ludwig L, Roberts D, Wiebe P, Younes M. Noninvasive positive-pressure ventilation in acute respiratory distress without prior chronic respiratory failure. Am J Respir Crit Care Med 1996;153(3):1005-1011.

35. Mehta S, Jay GD, Woolard RH, Hipona RA, Connolly EM, Cimini $\mathrm{DM}$, et al. Randomized, prospective trial of bilevel versus continuous positive airway pressure in acute pulmonary edema. Crit Care Med 1997;25(4):620-628.

36. Diaz O, Iglesia R, Ferrer M, Zavala E, Santos C, Wagner PD, et al. Effects of noninvasive ventilation on pulmonary gas exchange and hemodynamics during acute hypercapnic exacerbations of chronic obstructive pulmonary disease. Am J Respir Crit Care Med 1997; 156(6): 1840-1845

37. Slutsky AS, Ranieri VM. Ventilator-induced lung injury. N Engl J Med 2013;369(22):2126-2136.

38. Chastre J, Fagon JY. Ventilator-associated pneumonia. Am J Respir Crit Care Med 2002;165(7):867-903.

This article is approved for Continuing Respiratory Care Education credit. For information and to obtain your CRCE

(free to AARC members) visit www.rcjournal.com 